\section{News About the Tiny Pharmacists Within Us}

$\mathbf{M}$ mother was sure that diet and health were intertwined. Growing up, I survived on skim milk, fruit, and vegetables. Since she had a tight budget, we also had only the leanest and cheapest meat, which regularly included beef tongue (it's not bad if it's fixed right!). Other kids I knew got to eat potato chips and hot dogs, and I deeply envied them. It's not surprising, then, that I begged to go to Hamburger Heaven for my birthday lunch or to Trader Vic's for any celebration. All those carbs and fats: yum!

Of course, my mom was right. We know that eating too many carbs and fats makes us fat, which definitely is not healthy. However, as I studied nutrition in medical school and later as a physician, I began to realize just how little we really know about the link between diet and health. Despite a lot of dedicated work by epidemiologists, showing more than associations between disease and certain dietary habits is difficult. The public is constantly assailed by makers of supplements such as probiotics with unproven claims that altering your gut flora with organisms such as lactobacillus bulgaricus will keep you healthy.

Lately though, some revelations about the role of the gut microbiome and health have become compelling. We are starting to see real evidence that diet, likely through changes in the microbiome, can make a genuine difference. In December, a provocative study conducted by investigators at the $\mathrm{NCl}$ and the University of Texas MD Anderson Cancer Center was published in the journal Science. ${ }^{1}$ In a mouse model of melanoma, the researchers showed convincingly that a high-fiber diet delayed disease progression in mice treated with immune checkpoint therapy. A similar experiment in germ-free mice showed no effect, suggesting that the presence of gut flora really mattered. Remarkably, mice fed probiotics showed accelerated tumor progression.

In the clinical component of the study, the researchers evaluated dietary fiber intake in patients with melanoma treated with immune checkpoint therapy. Those who consumed more than 20 grams a day survived the longest without disease progression. And the effect seemed to be "dose-related" according to the amount of dietary fiber consumed.

Of course, the jury is still out regarding the precise mechanism behind these observations, but it does suggest that the bacteria that emerge in the presence of a high-fiber diet produce compounds that can act as immune adjuncts, enhancing the response to checkpoint blockade.

Designing and executing the clinical trial that proves dietary fiber matters will take some fancy footwork. After all, the public is quick to adopt dietary changes even if the evidence is slim. Perhaps the answer lies in identifying the ideal microbiome profile for effective immunotherapy and implementing fecal microbiome transplants along with adoption of a high-fiber diet to maintain it. It's a thought.

Now if you'll excuse me, I need a snack. Maybe some broccoli!

\section{Reference}

1. Spencer CN, McQuade JL, Vancheswaran G, et al. Dietary fiber and probiotics influence the gut microbiome and melanoma immunotherapy response. Science 2021;374:1632-1640. JNCCN@nccn.org or log into www.editorialmanager.com/JNCCN.

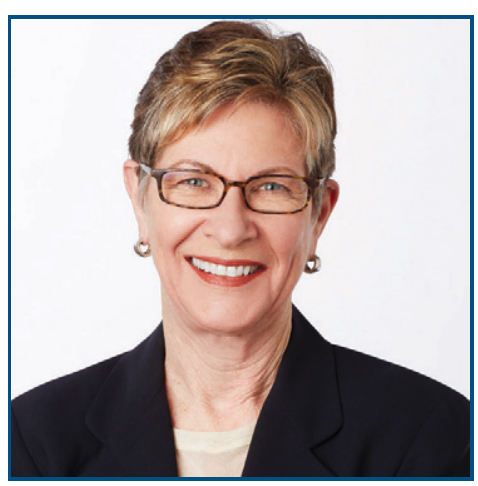

MARGARET TEMPERO, MD

Margaret Tempero, MD, is a Professor of Medicine and Director of the UCSF Pancreas Center and editor-in-chief of JNCCN. Her research career has focused on pancreatic ductal adenocarcinoma, especially in the area of investigational therapeutics. Dr. Tempero has served on the ASCO Board of Directors and as ASCO President. She currently serves on the ASCO Conquer Cancer Foundation Board. She codirected the AACR/ASCO Methods in Clinical Cancer Research and taught this course and similar courses in Europe and Australia. She was founding Chair of the $\mathrm{NCl}$ Clinical Oncology Study Section and served as a member and Chair of the $\mathrm{NCl}$ Board of Scientific Counselors Subcommittee A. She is a member of the Scientific Steering Committee and Chair of the Clinical and Translational Study Section for the Cancer Prevention \& Research Institute of Texas. She is or has been on the Scientific Advisory Boards of the Lustgarten Foundation, the Pancreatic Cancer Action Network, the V Foundation, The Alberta Canada Cancer Board, and the EORTC. She served as a member of the Oncology Drug Advisory Committee for the FDA. She has served as Deputy Director and Interim Director for the UNMC Eppley Cancer Center. She is Chief Emeritus of the Division of Medical Oncology at UCSF. She served as the founding Deputy Director and was later Director of Research Programs at the UCSF Helen Diller Family Comprehensive Cancer Center.

doi: 10.6004/jncen.2022.0010

The ideas and viewpoints expressed in this editorial are those of the author and do not necessarily represent any policy, position, or program of NCCN. 